\title{
HIPÓTESES E INTERPRETAÇÃO EXPERIMENTAL: A CONJETURA DE POINCARÉ E A DESCOBERTA DA HIPERFOSFORESCÊNCIA POR BECQUEREL E THOMPSON
}

\section{Hypothesis and experimental interpretation: Poincarés conjecture and the discovery of hyperphosphorescence by Becquerel and Thompson}

Roberto de Andrade Martins ${ }^{1}$

Resumo: Este trabalho descreve as pesquisas realizadas por Henri Becquerel e por Silvanus Thompson, em 1897, que são normalmente descritas como representando a descoberta da radioatividade. No entanto, o estudo histórico detalhado desse episódio mostra que os pesquisadores em questão tinham uma interpretação sobre os fenômenos que estudaram muito diferente da atual. Sua interpretação, segundo a qual haviam descoberto a "hiperfosforescência", baseava-se nos pressupostos que guiaram seus experimentos - como a conjetura de Henri Poincaré, de que havia uma relação entre a emissão de raios X em um tubo de Crookes e a luminescência do vidro. Este estudo de caso mostra como a observação científica é guiada por idéias pré-existentes, e quão difícil é interpretar os fenômenos observados. Este exemplo histórico pode ser utilizado no ensino, para apresentar uma visão mais adequada do que a ordinária, a respeito do próprio processo de pesquisa experimental.

Unitermos: Becquerel, Henri; Thompson, Silvanus; Poincaré, Henri; radioatividade; História da Física; método experimental; Ensino de Ciências

Abstract: This work describes the research developed by Henri Becquerel and Silvanus Thompson, in 1897, that are usually described as the discovery of radioactivity. However, the detailed historical scrutiny of this episode shows that those researchers had an interpretation of the phenomena they studied that was widely different from the one accepted nowadays. Their interpretation that they had discovered a phenomenon called "hyperphosphorescence" was grounded upon the presuppositions which guided their experiments - such as Henri Poincare's conjecture that there was a relation between the emission of $X$ rays by a Crookes tube, and the luminescence of its glass. This case study shows how scientific observation is guided by preexisting ideas, and how difficult it is to interpret the observed phenomena. This historical example can be used in teaching, to present a view on the process of experimental research, that is more adequate that the ordinary one.

Keywords: Becquerel, Henri; Thompson, Silvanus; Poincaré, Henri; radioactivity; History of Physics; experimental method; Science Teaching

\section{Introdução}

É muito comum encontrar entre alunos e professores de física, de todos os níveis, uma visão empirista da Ciência, segundo a qual o cientista faz observaçôes, de forma neutra e isenta de teorias, e depois chega a hipóteses baseado em suas observações ${ }^{2}$. No entanto, o estudo cuidadoso da História da Ciência mostra que não é esse o procedimento do pesquisador. Ao contrário da visão simplista que costuma ser transmitida pelos professores, há atualmente um consenso entre filósofos e historiadores da ciência sobre alguns pontos básicos a respeito da natureza da Ciência, que podem e devem ser transmitidos aos estudantes. Alguns deles estão enfatizados no currículo nacional de Ciências da Grã-Bretanha (PUMFREY, 1991):

\footnotetext{
${ }^{1}$ Professor Assistente Doutor, Grupo de História e Teoria da Ciência, DRCC-IFGW-Unicamp, Caixa Postal 6059, CEP 13081-970, Campinas, SP, Brasil. (e-mail: rmartins@ifi.unicamp.br) O autor agradece à Fapesp e ao CNPqo apoio recebido para a realização desta pesquisa.

${ }^{2}$ Ver, por exemplo, o modo como Dudley Towne apresentou o estudo das cores por Newton (Towne, 1993), e a nossa critica a essa abordagem (MARTINS \& SILVA, 2001; SILVA \& MARTINS, 2003).
} 
1) A observação inicial não é possível sem idéias pré-existentes.

2) A natureza não apresenta evidências suficientes para que seja interpretada sem ambigüidades.

3) As teorias científicas não são induções, mas hipóteses imaginadas pelos cientistas e necessariamente vão além das observações.

4) As teorias científicas não podem ser provadas.

5) O conhecimento científico não é estático e convergente, mas mutável e aberto.

6) O treino é um componente essencial para se compreender a Ciência.

7) O raciocínio científico é influenciado por fatores sociais, morais, espirituais e culturais.

8) Os cientistas não elaboram deduções incontestáveis, mas fazem julgamentos complexos.

9) Desacordo é sempre possível.

Não é, evidentemente, por terem sido incluidos no currículo britânico, que eles devem ser levados em conta por nós. Todos esses pontos podem ser defendidos e exemplificados por meio de numerosos exemplos históricos.

Os dois primeiros dos pontos indicados acima são especialmente relevantes no caso do trabalho experimental. Pelo estudo cuidadoso de alguns exemplos históricos, é possível mostrar aos estudantes quão complexa é a interpretação dos fatos observados pelo cientista. Assim, é muito útil, sob o ponto de vista educacional, analisar um episódio da História da Física que mostra exatamente esses aspectos.

A descoberta da radioatividade é muito citada como um exemplo de descoberta científica ao acaso. Este artigo procurará mostrar que as pesquisas de Henri Becquerel sobre a radiação emitida pelo urânio não se deram ao acaso, mas sim foram guiadas por hipóteses que atualmente consideramos errôneas; e que Becquerel tinha tal confiança nessas hipóteses que foi levado a cometer um grande número de erros em sua pesquisa. A descoberta de Becquerel (assim como a descoberta simultânea do mesmo fenômeno por Silvanus Thompson) será descrita em seu contexto científico, tal como os pesquisadores coetâneos a interpretaram: como um entre muitos exemplos de emissão de radiações penetrantes por corpos luminescentes.

\section{Raios X e luminescência: a conjetura de Poincaré}

A descoberta da radioatividade está intimamente associada ao anúncio de Röntgen sobre a existência dos raios X (RÖNTGEN, 1895). ${ }^{3}$ No início de Janeiro de 1896 Wilhelm Conrad Röntgen enviou pelo correio cópias de seu primeiro artigo aos principais líderes científicos da época. Em poucas semanas, seu trabalho começou a ser discutido e reproduzido em todo o mundo (JAUNCEY, 1945; GLASSER, 1933). Mais de mil artigos sobre raios X foram publicados durante o ano de 1896. O interesse sobre o assunto foi imenso, e em 1901 Röntgen recebeu o primeiro Prêmio Nobel de Física, por essa descoberta.

No seu primeiro artigo, Röntgen já fora capaz de estabelecer muitas propriedades físicas dos raios $\mathrm{X}$, mas durante vários anos a natureza dessa radiação permaneceu desconhecida. As principais hipóteses (POINCARÉ, 1897) aventadas sobre a natureza desses raios eram: (a) poderiam ser ondas eletromagnéticas transversais de pequeno comprimento de onda, semelhantes à radiação ultravioleta; (b) poderiam ser ondas eletromagnéticas longitudinais (hipótese levantada pelo próprio Röntgen); (c) poderiam ser pulsos não periódicos de radiação eletromagnética (hipótese

\footnotetext{
${ }^{3}$ Uma tradução comentada para o português encontra-se em Martins, 1998a. A metodologia empregada na pesquisa de Röntgen é analisada em Martins, 19986.
} 
proposta por Stokes); (d) poderiam, enfim, ser de natureza corpuscular, formados por raios catódicos modificados (neutros).

Além de não se compreender a natureza dos raios $\mathrm{X}$, não se sabia como eles eram produzidos pela descarga elétrica nos tubos de Crookes. Os raios $\mathrm{X}$ foram discutidos na Academia Francesa de Ciências, pela primeira vez, no dia 20 de janeiro de 1896 - poucas semanas após a publicação do primeiro trabalho de Röntgen. Henri Poincaré havia recebido diretamente de Röntgen uma separata de seu trabalho, assim como cópias de radiografias, e apresentou à Academia um relato verbal sobre a descoberta. Apresentou também à Academia as primeiras radiografias produzidas em Paris. Ele comentou sobre a importância do novo fenômeno e se mostrou profundamente interessado pelo mesmo.

Quando um tubo de Crookes é atravessado por uma descarga elétrica e emite raios $\mathrm{X}$, observava-se que a parede do tubo de vidro defronte ao cátodo fica luminescente, com um brilho amarelo-esverdeado. Era dessa região que os raios X eram emitidos. ${ }^{4}$ Poincaré conjeturou que talvez houvesse alguma relação entre a emissão de raios X e a fluorescência do vidro:

\begin{abstract}
Portanto, é o vidro que emite os raios de Röntgen, e ele se torna fluorescente ao emiti-los. Podemos nos perguntar se todos os corpos que possuem uma fluorescência suficientemente intensa não emitiriam os raios $X$ de Röntgen, além de raios luminosos, seja qual for a causa de sua fluorescência. Nesse caso, o fenômeno não estaria associado a uma causa elétrica. Isso não é muito provável, mas é possivel, e sem dúvida é fácil de verificar (POINCARÉ, 1896, p. 56).
\end{abstract}

Chamaremos essa hipótese, daqui por diante, de "conjetura de Poincaré". Ela logo foi testada, levando a importantes descobertas que serão descritas a seguir, e foi a fonte do trabalho de Becquerel com urânio. É claro que, de acordo com nosso conhecimento presente, não há relação direta entre os raios X e a luminescência observada, mas essa pista falsa serviu heuristicamente para guiar a descoberta de muitos fenômenos novos.

\title{
Primeiras confirmações da conjetura de Poincaré
}

Nas semanas que se seguiram ao anúncio da descoberta de Röntgen, foram apresentados à Academia Francesa de Ciências diversos trabalhos associados aos raios X. Entre outras coisas, havia uma busca de diferentes modos de produzir essas radiaçóes. Na reunião de 3 de fevereiro de 1896, Nordon relatou que um arco voltaico não produz raios X mas Moreau descreveu que eles eram emitidos por uma descarga de alta voltagem de uma bobina de indução (MOREAU, 1896), sem o uso de um tubo de vácuo (e, portanto, sem a intervenção de raios catódicos). Na mesma sessão, Benoist e Hurmuzescu relataram que os raios X eram capazes de descarregar um eletroscópio (BENOIST \& HURMUZESCU, 1896) - um fenômeno que teria uma importância muito grande em pesquisas posteriores. ${ }^{5}$

$\mathrm{Na}$ sessão semanal seguinte (10 de fevereiro de 1896), Charles Henry relatou o primeiro teste da conjetura de Poincaré (HENRY, 1896). Esse trabalho foi apresentado à Academia pelo próprio Henri Poincaré. Charles Henry testou primeiramente se o sulfeto de zinco fosforescente era capaz de aumentar o efeito dos raios X produzidos por um tubo de Crookes. Suas observaçóes o levaram a concluir que sim. Ele cobriu parte de um objeto metálico com uma camada de sulfeto de zinco, e descreveu que a radiografia desse objeto era mais forte e mais nítida abaixo da

\footnotetext{
${ }^{4}$ Não se usava o anti-cátodo, inicialmente.

${ }^{5}$ Röntgen, independentemente, também descobriu a descarga elétrica produzida pelos raios $X$, mas demorou um pouco a publicar seu trabalho. Ver Martins, 1997a.
} 
região com o material fosforescente. Depois, Henry testou a emissão de raios X pela mesma substância, quando estimulada pela luz (sem o uso do tubo de Crookes). Ele relatou que era possível obter radiografias sem utilizar tubos de raios $\mathrm{X}$, cobrindo o objeto a ser radiografado com uma camada de sulfeto de zinco e excitando sua fosforescência pela queima de uma tira de magnésio, em seu laboratório. A conjetura de Poincaré havia sido confirmada.

$\mathrm{Na}$ reunião da semana seguinte (17 de fevereiro de 1896), Gaston Henri Niewenglowski apresentou uma confirmação dos resultados de Charles Henry. Ele utilizou uma outra substância fosforescente - sulfeto de cálcio - e descreveu que essa substância, exposta ao Sol, emitia radiações capazes de penetrar papel preto totalmente opaco à luz comum e de sensibilizar uma chapa fotográfica (NIEWENGLOWSKI, 1896). Portanto, de acordo com as observaçôes descritas por esses dois pesquisadores, os materiais fosforescentes estudados pareciam emitir raios $\mathrm{X}$, quando excitados pela luz solar. Além disso, Niewenglowski também testou se o sulfeto de cálcio continuaria a emitir raios $\mathrm{X}$ quando fosse colocado em um local escuro, depois de receber a luz solar. Era natural testar a presença de emissão de radiaçôes penetrantes no escuro, pois o sulfeto de cálcio possui uma fosforescência visível de longa duração e poderia, portanto, continuar a emitir raios X, de acordo com a conjetura de Poincaré. Niewenglowski concluiu que essa substância continuava a emitir radiaçóes penetrantes no escuro: "Eu também observei que a luz emitida no escuro pelo pó fosforescente, previamente iluminado pelo Sol, era capaz de passar através de várias camadas de papel vermelho e de escurecer um papel sensível que estava blindado por essas camadas de papel" (NIEWENGLOWSKI,1896).

Note-se que esses experimentos não eram realizados ao acaso. Os pesquisadores estavam sendo guiados pela hipótese de Poincaré a respeito do processo de geração dos raios $\mathrm{X}$ e por seus conhecimentos a respeito do comportamento de materiais luminescentes. Todos esses resultados chocarão qualquer físico atual como estranhos ou mesmo impossíveis. Atualmente acreditamos que os corpos luminescentes não emitem, em geral, raios X. Aliás, mesmo no primeiro trabalho de Röntgen era afirmado claramente que os raios $\mathrm{X}$ podiam ser gerados quando os raios catódicos atingiam alumínio, e portanto, sem produzir qualquer luminescência. ${ }^{6}$ Os experimentos de Henry e Niewenglowski não deveriam ter dado os resultados descritos acima. O que aconteceu neles? Não somos capazes de compreendê-los.?

Embora, para nós, os resultados descritos por Henry e por Niewenglowski pareçam anômalos (não deveriam ter dado os resultados descritos), não sofreram críticas ou reaçōes negativas na época. Pelo contrário, foram considerados importantes comprovaçôes da hipótese de Poincaré.

Em outros países, também foram realizados experimentos semelhantes. J. J. Thomson havia chegado independentemente à conjetura de Poincaré ${ }^{8} \mathrm{e}$ a testou. No entanto, não observou emissão de radiaçōes penetrantes: "Observa-se que pode haver uma fosforescência vívida, sem qualquer produção desses raios” (THOMSON, 1896). Nos Estados Unidos, o pesquisador Carey Lea, depois de tomar conhecimento do experimento de Charles Henry e da conjetura de Poincaré, também fez um teste com outras substâncias, e foi o primeiro a testar um composto fluorescente de urânio:

\footnotetext{
${ }^{6}$ Ver os parágrafos 12-13 da tradução do artigo de Röntgen, em Martins, 1998a. Isso logo foi confirmado por Perrin, que negou a existência de qualquer relação entre luminescência e emissão de raios X (PERRIN, 1896).

${ }^{7} O$ aumento do efeito fotográfico de raios $X$ por corpos luminescentes poderia ser explicado parcialmente. Naquela época, as chapas fotográficas não eram muito sensiveis a raios X "duros" (de pequeno comprimento de onda). Algumas substâncias podem transformar raios $X$ duros em "moles" (de maior comprimento de onda). Embora os raios $X$ moles possuam uma menor energia (e menos poder de penetração), produzem um efeito fotográfico maior - exatamente porque sua absorção pela matéria é mais forte. No entanto, esse efeito não poderia explicar todos os fatos descritos por Charles Henry e Gaston Henri Niewenglowski.

${ }^{8}$ THOMSON, 1896. Esse artigo foi lido no dia 27 de janeiro de 1896, e é improvável que Thomson pudesse ter recebido qualquer informação sobre a conjetura de Poincaré antes daquela data.
} 
Hipóteses e interpretação experimental...

\begin{abstract}
Pareceu-me válido determinar se esse princípio é de aplicação geral. Uma solução de uranina foi exposta ao Sol, usando uma grande superfície da solução de modo a obter o melhor efeito. A uma pequena distância, sobre a superficie, foi colocado um filme sensivel protegido por uma folha de aluminio de 1/10 de milimetro de espessura e com uma estrela de chumbo interposta. Duas horas de exposição não deram resultado. O experimento foi repetido com solução ácida de quinino, que não deu resultado com uma exposição de cinco horas (LEA, 1896).
\end{abstract}

É plausível que Lea não tenha observado nenhum efeito da solução de urânio porque ela estava diluída e espalhada sobre uma grande superfície. O tempo de exposição era também curto. Note, no entanto, que era natural, nessa época, testar se os compostos fluorescentes de urânio (ou de qualquer outra substância) emitiam raios X.

Em Paris, na mesma sessão em que o trabalho de Piltchikof foi apresentado, Henri Becquerel descreveu sua primeira pesquisa sobre a emissão de raios $\mathrm{X}$ por corpos fosforescentes.

\title{
O primeiro artigo de Henri Becquerel sobre "radioatividade"
}

Antoine-Henri Becquerel ${ }^{9}$ pertenceu à terceira geração de uma famosa família de cientistas. Seu avô, Antoine-César Becquerel (1788-1878), é conhecido por seus estudos sobre eletroquímica, piezoeletricidade, termoeletricidade e eletricidade voltaica (KNIGHT, 1981; BECQUEREL, 1892). Entre muitos outros trabalhos, Antoine-César publicou uma obra monumental sobre eletricidade e magnetismo (Traité expérimental de l'éléctricité et du magnétisme, em sete volumes) que foi utilizada como trabalho de referência durante décadas. Um dos filhos de Antoine-César foi Alexandre-Edmond Becquerel (1829-1891), que também foi um físico bem conhecido (GOUGH, 1981; VIOLLE, 1892; HARVEY, 1957; W. C., 1892). Inicialmente ele trabalhou com seu pai e se dedicou ao estudo de vários fenômenos eletromagnéticos (eletroquímica, diamagnetismo). Sua contribuição mais importante, no entanto, foi sobre luminescência. Ele foi a principal autoridade sobre fosforescência e fluorescência em sua época.

Antoine Henri Becquerel (1852-1908), filho de Alexandre-Edmond, começou sua carreira científica seguindo os passos do pai. Suas principais investigaçōes foram sobre fenômenos ópticos - especialmente fosforescência (ROMER, 1981). Ele se familiarizou com radiações ultravioletas e infravermelhas, e estudou o efeito da radiação infravermelha na liberação de luz por algumas substâncias fosforescentes (BECQUEREL, 1884a, 1884b, 1891). Estudou a maioria das substâncias luminescentes que haviam sido colecionadas por seu pai - incluindo alguns compostos de urânio (BECQUEREL, 1885). Dentre os compostos de urânio que são fosforescentes ou fluorescentes, Edmond Becquerel tinha estudado o nitrato, cloreto, fluoreto duplo de urânio e potássio, silicato ("vidro de urânio"), fosfato, sulfato duplo de urânio e potássio etc. (BECQUEREL, 1859, 1872). A maioria dessas substâncias possui uma fosforescência de duração muito curta (alguns milisegundos). Naquela época, os compostos de urânio eram um assunto interessante para pesquisa sobre luminescência, por diversas razōes: havia muitas substâncias fosforescentes diferentes que continham urânio, e sua fluorescência era excepcionalmente forte.

Além disso, havia uma outra razão mais profunda para testar se os compostos de urânio emitiam raios X: de acordo com um modelo teórico aceito por Henri Becquerel para o processo de absorção e emissão de luz na fosforescência e na fluorescência, era plausível que no caso específico dos compostos de urânio pudesse ocorrer uma violação da Lei de Stokes e emissão de radiação de comprimento de onda menor do que a radiação absorvida (ver MARTINS, 1997b).

\footnotetext{
${ }^{9}$ O nome completo é Antoine-Henri Becquerel, mas ele sempre assinava seus trabalhos cientificos (e até mesmo sua correspondência) como Henri Becquerel.
} 
Os primeiros trabalhos de Henri Becquerel sobre "radioatividade" ${ }^{10}$ são bem conhecidos e foram traduzidos para o inglês várias vezes (por exemplo, em ROMER, 1964; BOARSE \& MOTZ, 1966). Suas pesquisas foram publicadas inicialmente como uma série de pequenas notas, nos Comptes Rendus da Academia de Ciências de Paris. Por causa de sua base científica, era natural que Henri Becquerel se interessasse pela conjetura de Poincaré e tentasse testá-la.

A primeira pesquisa de Becquerel sobre a relação entre raios X e luminescência foi apresentada à Academia de Ciências no dia 24 de fevereiro de 1896 (BECQUEREL, 1896a). Nessa comunicação, ele primeiramente reconheceu os estudos anteriores de Charles Henry e Niewenglowski, sem qualquer crítica ou restrição. Ou seja: no seu primeiro artigo, Henri Becquerel aceitou que os corpos luminescentes emitem raios X (ou algo semelhante a eles) e relatou um novo exemplo do fenômeno previamente descrito por Charles Henry e Niewenglowski ${ }^{11}$. $\mathrm{O}$ primeiro experimento de Becquerel é extraordinariamente semelhante aos de seus predecessores:

\begin{abstract}
Realizei o seguinte experimento com sulfato duplo de urânio e potássio, dos quais possuo alguns cristais que formam uma crosta fina, transparente. ${ }^{22}$ Uma chapa fotográfica de Lumière é embrulhada em duas folhas de papel preto muito espessas, de tal modo que a chapa não se escurece mesmo quando exposta ao Sol durante um dia inteiro. Um floco da substância fosforescente é colocado sobre o papel, fora dele, e o conjunto é exposto ao Sol por várias horas. Quando a chapa fotográfica é revelada, aparece a silhueta da substância fosforescente em preto, no negativo. Se for colocada uma moeda ou uma chapa metálica furada entre a substância fosforescente e o papel, suas imagens serão visiveis no negativo. O mesmo experimento pode ser repetido colocando uma placa fina de vidro entre a substância fosforescente e o papel. Isso exclui a possibilidade de qualquer ação quimica por vapores que pudessem escapar da substância quando ela é aquecida pelos raios do Sol. É possivel concluir desses experimentos que esta substância fosforescente emite radiaçôes que atravessam um papel opaco à luz e reduzem os sais de prata (BECQUEREL, 1896a).
\end{abstract}

O único aspecto relevante novo do primeiro artigo de Becquerel foi o uso de uma nova substância - o sulfato duplo de urânio e potássio. $\mathrm{O}$ resultado principal foi semelhante aos de Henry e Niewenglowski.

\title{
A “descoberta da radioatividade" por Becquerel
}

Na reunião da Academia de Ciências da semana seguinte (2 de março de 1896), d'Arsonval comunicou que havia sido capaz de produzir radiografias utilizando uma lâmpada fluorescente e colocando um vidro fluorescente sobre os objetos a serem radiografados (D'ARSONVAL, 1896). Esse vidro fluorescente continha um sal de urânio. A conclusão de d'Arsonval foi que todos os corpos que emitem luz fluorescente amarelo-esverdeada também emitem radiaçôes que são capazes de impressionar chapas fotográficas envoltas em papel opaco à luz.

$\mathrm{Na}$ mesma sessão, Henri Becquerel apresentou um segundo artigo - aquele que é usualmente descrito como contendo a descoberta da radioatividade (BECQUEREL, 1896b). Nesse segundo artigo, Becquerel descreveu novas observações sobre os efeitos produzidos por seus cristais de sulfato duplo de urânio e potássio. Comparou essas radiações às produzidas por

\footnotetext{
${ }^{10}$ Em 1896, nem o nome "radioatividade" nem o conceito correspondente existiam, mas, seguindo a tradição, vamos nos referir anacronicamente aos artigos de Becquerel sobre "radioatividade" dessa época.

${ }^{11}$ Em um trabalho muito posterior, Becquerel criticou o trabalho de Charles Henry e sugeriu que os efeitos observados fossem devidos à pressão produzida pela moeda sobre a placa fotográfica: Becquerel, 1903a, p. 4-5.

${ }_{12}$ Os cristais utilizados por Becquerel não possuiam a forma geométrica regular que costumamos associar ao nome "cristal". Tinham uma aparência irregular, parecida com a forma de flocos de milho.
} 
tubos de raios $\mathrm{X}$, notando que elas possuíam poderes de penetração diferentes. Relatou que a emissão de radiação penetrante ocorria quando a substância fosforescente estudada recebia a luz solar diretamente, ou refletida por um espelho, ou refratada. ${ }^{13}$ A parte do artigo que supostamente relata a descoberta da radioatividade é a seguinte:

Insistirei particularmente sobre o seguinte fato, que me parece muito importante e estranho ao dominio dos fenômenos que se esperaria observar. Os mesmos flocos cristalinos, colocados junto às chapas fotográficas, nas mesmas condiçôes, isolados pelos mesmos anteparos, mas sem receber excitação pela incidência de radiação e mantidos no escuro, ainda produzem as mesmas impressóes fotográficas. Este foi o modo pelo qual fui levado a fazer essas observaçôes: entre os experimentos precedentes, alguns foram preparados na quarta-feira, 26, e na quinta-feira, 27 de fevereiro; $e$ como, nesses dias, o Sol apareceu apenas de modo intermitente, guardei os experimentos que havia preparado e coloquei as chapas com seus envoltórios na obscuridade da gaveta de um móvel, deixando os flocos de sal de urânio em seu lugar. Como o Sol não apareceu novamente nos dias seguintes, no dia 1 de março eu revelei as chapas fotográficas, esperando encontrar imagens muito fracas. Pelo contrário, as silhuetas apareceram com uma forte intensidade. Eu logo pensei que a ação devia ter continuado na obscuridade [...] (BECQUEREL, 18966).

Por que motivo essa nova observação foi descrita como "inesperada”? Não era a existência de radiações penetrantes que Becquerel considerava estranha, e sim a emissão dessas radiações no escuro: "Parece que esse fenômeno não deve ser atribuído a radiaçōes luminosas emitidas por fosforescência, pois após um centésimo de segundo essas radiações se tornam tão fracas que são dificilmente perceptíveis" (BECQUEREL, 1896b). Será que isso mostrou a Becquerel que ele estava diante de um fenômeno completamente novo, estranho a tudo o que a física havia descoberto até então? De modo nenhum. O ponto de partida de Becquerel havia sido a hipótese (implícita) de que os corpos luminescentes emitiriam raios $\mathrm{X}$ enquanto estivessem luminosos. No caso do experimento de Niewenglowski, a emissão de raios X pelo sulfeto de cálcio no escuro era algo que devia ser esperado, pois a fosforescência dessa substância tem longa duração (várias horas). Becquerel esperava um efeito muito fraco de seus cristais, já que sua fosforescência visível diminuía muito rapidamente, no escuro.

Esse efeito forte observado era inesperado, mas poderia ser explicado de acordo com conhecimento da época a respeito da fosforescência. Realmente, é necessário apenas ler os trabalhos do pai de Henri Becquerel para encontrar um fenômeno semelhante. A duração de diferentes cores de luz emitidas por uma dada substância fosforescente podem ser muito diferentes (BECQUEREL, 1859, p. 117). Em alguns casos, os comprimentos de onda mais longos possuem uma duração maior (como no caso do sulfato de quinino e no diamante); em outros, os comprimentos de onda mais curtos possuem maior duração (giz, cristal da Islândia - ou seja, calcita). Por essa razão, a cor resultante observável de uma substância fosforescente colocada no escuro geralmente muda com o tempo. Poderia ocorrer, portanto, que a fosforescência visivel de curta duração do cristal de urânio fosse acompanhada por uma fosforescência invisivel de longa duração, com emissão de radiação penetrante. Foi exatamente essa a explicação dada por Henri Becquerel:

\footnotetext{
${ }^{13}$ A motivação implicita desses testes era verificar se havia alguma parte especial do espectro solar que era responsável pelo estímulo à emissão da radiação penetrante. 
Uma hipótese que surge de modo natural à mente é a suposição de que essas radiaçôes, cujo efeito possui uma forte analogia com as produzidas pelas radiaçôes estudadas pelos senhores Lenard e Röntgen, poderiam ser radiaçôes invisiveis emitidas por fosforescência com uma persistência infinitamente maior do que a persistência das radiaçôes luminosas emitidas por esses corpos. No entanto, os experimentos relatados, embora não sejam contrários a essa hipótese, não nos permitem formulá-la. (BECQUEREL, 1896b, p. 503)

É interessante assinalar que a possibilidade de uma fosforescência invisível desconhecida já havia sido antecipada pelo pai de Henri Becquerel. De fato, Edmond Becquerel comentou que, mesmo no caso de substâncias que não exibiam fosforescência observável em seus experimentos, poderia haver algum efeito oculto e desconhecido e emissão de radiações eletromagnéticas fora do espectro visível (BECQUEREL, 1859, p. 117). Até esse ponto, portanto, Henri Becquerel estava longe de suspeitar que ele próprio havia observado algo semelhante ao nosso conceito de radioatividade. Tanto ele quanto os outros autores da época acreditavam estar detectando raios X. Em um artigo de revisão sobre raios X publicado em março de 1896, Raveau descreveu as pesquisas de Henry, Niewenglowski, Piltchikof, d'Arsonval e Becquerel como casos especiais do fenômeno predito por Poincaré e descoberto por Charles Henry (RAVEAU, 1896). Uma semana após a famosa comunicação de Becquerel sobre a radiação do sal de urânio mantido no escuro, a Academia de Paris ouviu uma nova confirmação da conjetura de Poincaré. Troost confirmou os experimentos de Charles Henry com sulfeto de zinco fosforescente (TROOST, 1896). Ele afirmou ter obtido fortes efeitos radiográficos quando a fosforescência da blenda era excitada por luz de magnésio. Troost se referiu aos trabalhos de Niewenglowski e Becquerel como investigaçōes sobre o mesmo fenômeno, predito por Poincaré.

\title{
A descoberta simultânea da hiperfosforescência por Silvanus Thompson
}

Quando as condições científicas para o surgimento de uma descoberta estão maduras, ocorre geralmente que a descoberta é feita simultaneamente por diversos pesquisadores independentes. Isso também ocorreu no caso da "fosforescência invisível" dos compostos de urânio. Na mesma época em que Henri Becquerel fazia seus primeiros experimentos, Silvanus Thompson também detectou o fenômeno - e o interpretou exatamente do mesmo modo que Becquerel.

Silvanus Phillips Thompson (1851-1916) não é muito conhecido atualmente. Sua principal área de trabalho era eletricidade, mas ele era também considerado como uma autoridade em luminescência, no final do século XIX. A descoberta de Thompson que nos interessa aqui é descrita da seguinte forma na sua biografia, escrita por suas filhas:

\begin{abstract}
Durante o mês de fevereiro [de 1896], Thompson e seu assistente, o sr. Miles Walker, estavam ocupados com vários experimentos, usando substâncias fluorescentes em contato com o filme fotográfico para acelerar a ação química quando estimuladas pelos raios $X$. Os materiais utilizados eram espato da Islândia [calcita] finamente pulverizado, sulfeto de zinco, fluoreto de urânio, e diversos platino-cianetos. Quando estava trabalhando, Thompson encontrou um efeito inesperado. Encontrou, ao revelar uma chapa fotográfica, que quando o nitrato de urânio ou o fluoreto de urânio e amônio haviam sido usados, ocorrera uma ação distinta através de uma folha de aluminio que era impenetrável aos raios $X$ [sic: which is impervious to $X$-rays]. ${ }^{14}$ Ele imediatamente escreveu para Sir George Stokes, que era então Presidente da Royal Society, no dia 26 de fevereiro, ${ }^{15}$ contando-lhe sua descoberta [...] (THOMPSON \& THOMPSON, 1920, p. 185). ${ }^{16}$
\end{abstract}

\footnotetext{
${ }^{14} E$ É claro que os raios $X$ passam através de placas fina de aluminio. Há algum erro no original.

${ }^{15} \mathrm{Na}$ verdade, a carta é datada de 28 de fevereiro de 1896, e não 26 de fevereiro.

${ }^{16}$ Há vários enganos nessa descrição, como ficará claro mais adiante. A data da carta a Stokes está errada, assim como o conteuido da carta.
} 
A biografia não apresenta o texto da carta de Thompson. Ela foi publicada, no entanto, na correspondência de Stokes (LARMOR, 1907, v. 2, p. 495): ${ }^{17}$

Fiz ontem uma observação de interesse tão curioso que resolvi chamar sua atenção para ela. Encontrei que se uma substância fosforescente tal como o sulfeto de bário é exposta à luz branca ordinária, de modo a ficar bem impregnada pelo Sol, e levada à condição de brilhar, ela emite depois (e aparentemente também durante a iluminação) não apenas a luz ordinária que pode ser barrada por uma folha de aluminio, mas também alguma coisa a mais que não é barrada pelo aluminio, e que é, pelo menos nesse ponto, igual aos raios $X$ de Röntgen, pois pode atravessar o aluminio e agir sobre uma chapa fotográfica. Se é verdade que há substâncias fluorescentes (ou fosforescentes) que se desviam da sua lei de degradação da freqüência (ou comprimento de onda), este pareceria apresentar um caso extremo de tal desvio. Mas se esses forem raios de Röntgen, então eu fui capaz de manufaturá-los a partir da luz comum por um tipo de processo reverso da fluorescência. Você conhece algum outro exemplo no qual se descobriu que a fluorescência ou fosforescência pode ter uma operação reversivel?

Note que Thompson escreveu a Stokes não porque ele era Presidente da Royal Society, mas sim porque ele era um especialista sobre luminescência. Na sua carta, Thompson não afirma nada sobre compostos de urânio - parece que o efeito mais notável havia sido observado com sulfeto de bário, já que essa é a única substância indicada nominalmente na $\operatorname{carta}^{18}$. Sabemos que o sulfeto de bário não é sensivelmente radioativo. O que ele teria observado?

Larmor, o editor da correspondência de Stokes, ficou intrigado com essa carta e perguntou a Thompson, que estava ainda vivo, sobre esse ponto. "[...] em resposta a uma questão, ele agora afirma que tinha estado testando várias substâncias, incluindo nitrato de urânio, e que ele havia encontrado de modo conclusivo, em 26-7 de fevereiro, que esta era a única à qual a folha de alumínio não era opaca, embora o papel negro fosse transparente aos outros" (LARMOR, 1907, v. 2, p. 496, segunda nota de rodapé). Não há, no entanto, documentação daquela época que corrobore a afirmação de Thompson.

A descrição da descoberta de Thompson foi publicada apenas alguns meses depois (ANÔNIMO, 1896; THOMPSON, 1896b). Ele testou vários materiais luminescentes bem conhecidos, incluindo sulfeto de cálcio, espato da Islândia, sulfeto de zinco, fluoreto de urânio e de amônio, e diversos platino-cianetos. Ele notou que alguns deles velavam filmes sensíveis, mesmo quando guardados no escuro por um longo tempo (espato da Islância e os platino-cianetos não possuíam esse poder). Nos primeiros experimentos, não havia um anteparo entre os corpos fosforescentes e a chapa fotográfica. Posteriormente, Thompson colocou uma folha de alumínio entre eles e, nesse caso, apenas o nitrato de urânio e o fluoreto de urânio e amônio afetavam a chapa fotográfica. Thompson chegou ao mesmo resultado que Becquerel: alguns compostos de urânio emitem radiaçôes penetrantes que persistem na obscuridade por um longo tempo. Não há documentos contemporâneos, no entanto, que permitam estabelecer a data exata de cada experimento realizado por Thompson.

\footnotetext{
${ }^{17}$ A carta original foi consultada na coleção de documentos de Stokes, em Cambridge: Carta de Thompson para Stokes, 28 de fevereiro de 1896, depositada na seção de manuscritos da Cambridge University Library (CUL), Add 7656.T329. Os demais manuscritos indicados abaixo foram também consultados em Cambridge e em Londres.

${ }^{18} \mathrm{O}$ sulfeto de bário tem forte fosforescência. Em uma nota curta publicada em Nature no dia 12 de março de 1896, percebe-se que Thompson estava também experimentando diversas substancias fosforescentes como anticátodo. Ele relatou que o sulfeto de cálcio, incorporado em um vidro, "parece formar uma excelente superfície anti-catódica para gerar raios X” (THOMPSON, 1896a).
} 
Imediatamente após receber a carta de Thompson, Stokes respondeu: "Sua descoberta é extremamente interessante; presumo que você a publicará sem demora, especialmente porque muitos estão agora trabalhando com raios X" (LARMOR, 1907, v. 2, p. 495). ${ }^{19}$ Poucos dias depois, Stokes escreveu novamente para Thompson, para lhe dar uma triste notícia: "Temo que você já tenha sido antecipado. Ver Becquerel, Comptes Rendus de Fev. 24, p. 420, e alguns artigos em duas ou três sessões antes dessa" (ibid., v. 2, p. 496). ${ }^{20}$

Note-se que Stokes aceitava que Thompson e Becquerel haviam descoberto o mesmo fenômeno. Isso pode ser notado também a partir de uma outra carta que Stokes enviou a Thompson alguns meses mais tarde:
P. S. Eu posso também mencionar, para o caso de que você não o tenha visto, que no último núme- ro dos Comptes Rendus há um artigo de Becquerel no qual ele menciona que o urânio metálico exibe o notável fenômeno que você e ele descobriram, independentemente, cerca de 4 vezes mais forte do que os sais de urânio que ele tinha usado antes (LARMOR, 1907, v. 2, p. 498). ${ }^{21}$

Por que Stokes mencionou apenas Becquerel, e não as pesquisas de Charles Henry e outros? Nessa época, era impossível distinguir o trabalho de Becquerel das outras confirmações da conjetura de Poincaré. Na carta de Stokes de 2 de março, acima referida, ele realmente indica artigos publicados antes do trabalho de Becquerel, e portanto estava se referindo a Henry e Niewenglowski. Depois, no entanto, Stokes passa a se referir apenas a Becquerel. Talvez isso tenha ocorrido porque Stokes o conhecia pessoalmente, além de estar há cinco décadas associado à família Becquerel. Por outro lado, Lord Kelvin, que havia sido informado sobre a descoberta de Silvanus Thompson, comparou-a ao trabalho de d'Arsonval:

\section{Notei que a descoberta muito interessante de Sylvanus [sic] Thompson tinha sido antecipada por d'Arsonval nos Comptes Rendus de 2 de março (WILSON, 1990, v. 2, p. 650, carta 555). ${ }^{22}$}

O que Thompson pensou ter encontrado? Como vimos, em sua primeira carta a Stokes ele havia interpretado o fenômeno descoberto como se fosse um tipo de fosforescência ou fluorescência invisível que violava a Lei de Stokes, e que produzia emissão de radiação de menor comprimento de onda do que a radiação incidente. Seria isso admissível, na época? No final do século XIX, aceitava-se que a Lei de Stokes representava uma lei geral, mas não destituída de exceções. O próprio Stokes informou a Thompson que a Lei não era completamente geral: "Esses efeitos são inconsistentes com uma lei enunciada por Stokes - mas que posteriormente ele modificou" (ANÔNIMO, 1896). Silvanus Thompson chamou o fenômeno observado de "hiperfosforescência" e descreveu-o da seguinte forma:

Este fenômeno, descoberto pelo autor independentemente ao mesmo tempo que Henri Becquerel, consiste na emissão persistente por certas substâncias, especialmente o urânio metálico e seus sais, de raios invisíveis que se assemelham muito aos raios de Röntgen por sua ação fotográfica, e por seu poder de penetrar o alumínio e produzir descarga elétrica (THOMPSON, 1896c).

\footnotetext{
${ }^{19}$ Uma cópia da carta original pode ser encontrada na coleção de documentos de Stokes: Carta de Stokes para Thompson, 29 de fevereiro de 1896, CUL Add 7656.T330. A carta original, datilografada, de Stokes para Thompson está guardada em Londres: Imperial College Archives, Silvanus P. Thompson's papers, carta 296.

${ }^{20}$ Uma cópia da carta original pode ser encontrada na documentação de Stokes: Carta de Stokes para Thompson, 2 de março de 1896, CUL Add 7656.T331. O original datilografado de Stokes para Thompson está depositado em: Imperial College Archives, Silvanus P. Thompson's papers, carta 297.

${ }^{21}$ Uma cópia da carta original pode ser encontrada na documentaçāo de Stokes: Carta de Stokes para Thompson, 28 de maio de 1896, CUL Add 7656.T332. A carta original de Stokes para Thompson está guardada em: Imperial College Archives, Silvanus P. Thompson's papers, carta 298.

${ }^{22}$ Carta de Lord Kelvin a Stokes, 12 de março de 1896, CUL Add 7656.K313.
} 
Qual era a natureza dessas radiaçôes? "Como suas propriedades [dos raios do urânio] são intermediárias entre as do ultravioleta e dos raios de Röntgen, isso fornece uma forte presunção de que os últimos são uma espécie extrema de luz ultravioleta, e apenas diferem deles em grau" (THOMPSON, 1896b, p. 106). Seguindo essa interpretação, Thompson tirou a mesma conclusão que Becquerel:

O fenômeno de emissão persistente desses raios invisiveis pelos compostos do urânio muito tempo depois que cessou a aplicação de qualquer estímulo elétrico ou luminoso pareceria, portanto, ter a mesma relação com a sua emissão temporária no tubo de Crookes que a emissão persistente de luz visivel por corpos fosforescentes tem com a emissäo temporária de luz por corpos fluorescentes. Por isso o autor se aventura a dar ao novo fenômeno, assim observado independentemente pelo sr. Becquerel e por ele próprio o nome de hiper-fosforescência. Um corpo hiper-fosforescente é aquele que, depois do estímulo adequado, exibe uma emissão persistente de raios invisiveis que não estão incluidos no espectro reconhecido até agora (THOMPSON, 18966).

Embora Thompson mencione Becquerel, este nunca mencionou o trabalho de Thompson. Na época, os cientistas atribuíram pequena importância ao trabalho do pesquisador inglês, provavelmente porque os resultados de Becquerel foram publicados alguns meses antes. Os historiadores da Ciência raramente se referem à sua contribuição ${ }^{23}$. No entanto, mesmo entre autores franceses, o nome "hiperfosforescência" cunhado por Thompson passou a ser amplamente aceito e usado para descrever o fenômeno estudado por Henri Becquerel (ver Guillaume, 1897, p. 131-5). O próprio Becquerel não propôs um nome novo, sempre descrevendo as radiações do urânio como um tipo de fosforescência invisível de longa duração. Foi Marie Curie (não Becquerel) quem pela primeira vez criticou esse nome e o conceito subjacente:

Chamarei de radioativas as substâncias que emitem os raios de Becquerel. O nome hiperfosforescência que foi proposto para of fenômeno parece-me transmitir uma idéia errada sobre sua natureza (CURIE, 1899).

\section{Comentários finais}

Visto em seu contexto, em meio ao enorme número de pesquisas sobre radiações penetrantes da época, no período de 1896 a 1897, o trabalho de Becquerel era apenas um entre muitos fenômenos estranhos relatados (JAUNCEY, 1946; BADASH, 1965). Em sua maior parte, essas pesquisas iniciais eram guiadas pela conjetura de Poincaré. Durante todos esse período, o próprio Becquerel não fez qualquer esforço para traçar uma distinção entre sua própria pesquisa e a de outras pessoas que haviam confirmado a conjetura de Poincaré.

A conjetura de Poincaré foi particularmente fértil, não porque tivesse alguma fundamentação teórica, mas porque era fácil expor chapas fotográficas a diversos corpos luminescentes e procurar algo semelhante aos raios X. Por outro lado, hipóteses como a sugestão de Röntgen sobre ondas longitudinais do éter eram muito mais difíceis de testar e levaram a um número limitado de publicaçôes. ${ }^{24}$

As hipóteses que guiaram Becquerel e Thompson impediram que eles percebessem tratar-se de um fenômeno totalmente novo. No caso de Becquerel, suas idéias prévias sobre a natureza do fenômeno levaram-no a realizar experimentos em que julgou ter observado que a

\footnotetext{
${ }^{23}$ Uma exceção é Badash, que cita seu nome, mas não proporciona informaçôes mais detalhadas sobre o trabalho de Thompson: Badash, 1965, p. 63, nota de rodapé 29.

${ }^{24}$ Ver, por exemplo, THOMSON, 1896, e KELVIN, 1896.
} 
radiação dos compostos de urânio se tornava mais intensa depois de excitada pela luz do Sol; que essa radiação diminuía quando os compostos eram mantidos no escuro; que a radiação do urânio podia ser refletida, refratada e polarizada do mesmo modo que a luz. ${ }^{25}$ Ou seja: a hipótese de Becquerel de que se tratava de um fenômeno de fosforescência invisível guiou suas pesquisas, e sua convicção era tão forte, que ele descreveu fenômenos inexistentes, que pareciam confirmar que a radiação emitida pelo urânio tinha propriedades semelhantes às da luz.

Os resultados descritos por Becquerel foram aceitos sem discussão, na época (SAGNAC, 1896; STEWART, 1898), porque estavam de acordo com as expectativas teóricas e porque havia poucas pessoas interessadas em estudar o novo fenômeno, que parecia desprovido de importância. Antes de 1898 - quando foi encontrada a emissão de radiações pelo tório - não se deu muita atenção à pesquisa de Becquerel. Ele próprio também parece ter acreditado que não se tratava de um assunto muito interessante - apenas um novo tipo de fosforescência invisível - e voltou sua atenção para um outro assunto: o efeito Zeeman. Nessa época, qualquer físico descreveria o que Becquerel e Thompson haviam feito como sendo a descoberta da hiperfosforescência, um fenômeno curioso, porém de forma nenhuma revolucionário ou importante.

Pode-se dizer que não foi Becquerel quem chamou a atenção do mundo para um fenômeno novo e estranho. Foi graças aos trabalhos de Schmidt e Curie que as radiações emitidas pelo urânio (e tório) foram claramente discernidas de outros efeitos, e se tornaram proeminentes. Foi Marie Curie e não Becquerel quem rejeitou o nome "hiperfosforescência" e cunhou o nome "radioatividade", abandonando a conjetura de Poincaré e chamando a atenção do mundo científico para uma nova classe de fenômenos. Pode-se considerar que Marie Curie foi responsável não apenas pelo nome "radioatividade", mas também pelo estabelecimento da radioatividade como um novo campo de pesquisas (MARTINS, 2003). Foi principalmente graças ao trabalho de Curie, com a descoberta da descoberta do tório, do polônio e do rádio, em 1898, que tornou o assunto amplamente conhecido e discutido. Assim a pesquisa da radioatividade começou a se tornar frutífera e se destacou do enxame de estranhos efeitos que zumbiam em torno dos raios $\mathrm{X}$.

A análise desse episódio histórico mostra a íntima relação entre o trabalho de laboratório e as hipóteses aceitas pelos pesquisadores, mostrando por meio de um exemplo específico quão distante a prática científica está de um modelo empirista ingênuo. Exemplos como este podem ser utilizados no ensino, para mostrar a real complexidade da pesquisa experimental e o modo como os pressupostos teóricos servem para orientar a experimentação e para interpretar aquilo que o pesquisador pensa estar observando. Note-se, no entanto, que as descriçōes históricas encontradas em livros-texto ou em obras elementares sobre História da Ciência contêm descrições não apenas simplificadas, mas também errôneas, e que apenas uma pesquisa detalhada de alguns episódios, baseando-se em fontes primárias (os documentos originais da época), permite mostrar a complexa dinâmica da pesquisa científica.

Infelizmente (para quem gosta de coisas simples), a história é complexa e tem aspectos que não podem ser compreendidos por pessoas às quais faltem certos pré-requisitos. Estudantes universitários de Ciências Exatas que já tenham passado pelas disciplinas básicas (mais especificamente a partir do $3 .^{\circ}$ ano) têm condiçôes de compreender tudo ou praticamente tudo o que está envolvido na história. No caso de pessoas sem tal formação, somente seria possível apresentar uma versão simplificada (e certamente não tão eficaz) do presente caso histórico.

Minha experiência com estudantes de graduação e de pós-graduação mostra que expôlos a uma descrição detalhada deste episódio (ou de outros semelhantes) produz um profundo

\footnotetext{
${ }^{25}$ Os limites impostos ao tamanho deste trabalho impossibilitam a discussão desses experimentos aqui. Para mais detalhes, ver MARTINS, 2000.
} 
impacto, ajudando a romper com a visão ingênua que se costuma ter sobre as "descobertas" e sobre a natureza do trabalho experimental. A História da Ciência pode assim contribuir para que os estudantes possam desenvolver uma visão mais adequada da própria natureza do trabalho científico.

\section{Referências}

[ANÔNIMO]. On the relations between kathode rays, Röntgen rays, and Becquerel rays. Report of the 66th Meeting of the British Association for the Advancement of Science [66]: 712, 1896.

BADASH, L. Radioactivity before the Curies. American Journal of Physics, New York, v. 33, p. 128-35, 1965.

BECQUEREL, A. E. La lumière, ses causes et ses effets. Paris: Firmin Didot frères, fils et cie., 1867-1968. 2 v.

. Recherches sur divers effets lumineux qui résultent de l'action de la lumière sur les corps. Composition de la lumière émise. Annales de Chimie et de Physique, Paris, v. 3, n. 57, p. 40-124, 1859.

. Mémoire sur l'analyse de la lumière émise par les composés d'uranium phosphorescents. Annales de Chimie et de Physique, Paris, v. 4, n. 27, p. 539-579, 1872.

BECQUEREL, H. Spectres d'émission infra-rouges des vapeurs métalliques. Comptes Rendus Hebdomadaires des Séances de l'Académie des Sciences, Paris, v. 99, p. 374-376, 1884a.

Détermination des longueurs d'onde des raies et bandes principales du spectre solaire infra-rouge. Comptes Rendus Hebdomadaires des Séances de l'Académie des Sciences, Paris, v. 99, p. 417-450, $1884 b$.

. Relations entre l'absorption de la lumière et l'émission de la phosphorescence dans les composés d'uranium. Comptes Rendus Hebdomadaires des Séances de l'Académie des Sciences, Paris, v. 101, p. 1252-1256, 1885.

- Sur les différentes manifestations de la phosphorescence des minéraux sous l'influence de la lumière ou de la chaleur. Comptes Rendus Hebdomadaires des Séances de l'Académie des Sciences, Paris, v. 112, p. 557-563, 1891.

. La chaire de physique du Muséum. Revue Scientifique, Paris, v. 49, p. 673-678, 1892.

. Sur les radiations émises par phosphorescence. Comptes Rendus Hebdomadaires des Séances de l'Académie des Sciences, Paris, v. 122, p. 420-421, 1896.

. Sur les radiations invisibles émises par les corps phosphorescents. Comptes Rendus Hebdomadaires des Séances de l'Académie des Sciences, Paris, v. 122, p. 501-503, 1896 b.

Recherches sur une propriété nouvelle de la matière - activité radiante spontanée ou radioactivité de la matière. Mémoires de l'Académie des Sciences de l'Institut de France, Paris, v. 46, p. 1-360, 1903. 
BENOIST, L. \& HURMUZESCU, D. Nouvelles propriétés des rayons X. Comptes Rendus Hebdomadaires des Séances de l'Académie des Sciences, Paris, v. 122, p. 235-236, 1896.

BOARSE, H. A. \& MOTZ, L. (Ed.). The world of the atom. New York: Basic Books, 1966. 2 v.

CURIE, M. S. Les rayons de Becquerel et le polonium. Révue Générale des Sciences, v. 10, p. 41-50, 1899.

D'ARSONVAL, A. Observation au sujet de la photographie à travers les corps opaques. Comptes Rendus Hebdomadaires des Séances de l'Académie des Sciences, Paris, v. 122, p. 500-501, 1896.

GLASSER, O. Wilhelm Conrad Röntgen and the early history of the Röntgen rays. London: John Bale, Sons \& Danielsson, 1933.

GOUGH, J. B. Becquerel, Alexandre-Edmond. In: GILLISPIE, C. C. (Ed.). Dictionary of scientific biography. New York: Charles Scribner’s Sons, 1981. v. 1, p. 555-556.

GUILLAUME, C. É. Les rayons $\mathrm{X}$ et la photographie a travers les corps opaques. 2. ed. Paris: Gauthier-Villars, 1897.

HARVEY, E. N. A history of luminescence from the earliest times until 1900. Philadelphia: American Philosophical Society, 1957.

HENRY, C. Augmentation du rendement photographique des rayons Roentgen par le sulfure de zinc phosphorescent. Comptes Rendus Hebdomadaires des Séances de l'Académie des Sciences, Paris, v. 122, p. 312-314, 1896.

JAUNCEY, G. E. M. The birth and early infancy of X-rays. American Journal of Physics, New York, v. 13 , p. 362-379, 1945.

1946.

The early years of radioactivity. American Journal of Physics, New York, v. 14, p. 226-241,

KELVIN, L. On the generation of longitudinal waves in ether. Proceedings of the Royal Society of London, London, v. 59, p. 270-272, 1896.

KNIGHT, D. M. Becquerel, Antoine-César. In: GILLISPIE, C. C. (Ed.). Dictionary of scientific biography. New York: Charles Scribner’s Sons, 1981. v. 1, p. 557-558.

LARMOR, J. (Ed.). Memoir and scientific correspondence of the late Sir George Gabriel Stokes. Cambridge: Cambridge University Press, 1907. 2 v.

LEA, M. C. Röntgen rays not present in sunlight. American Journal of Science, New Haven, v. 4, n. 1, p. 363-364, 1896.

MARTINS, R. de A. Como Becquerel não descobriu a radioatividade. Caderno Catarinense de Ensino de Física, Florianópolis, v. 7, p. 27-45, 1990. 
. Investigando o invisível: as pesquisas sobre raios X logo após a sua descoberta por Röntgen.

Revista da Sociedade Brasileira de História da Ciência, São Paulo, v. 17, p. 81-102, 1997a.

MARTINS, R. de A. Becquerel and the choice of uranium compounds. Archive for History of Exact Sciences, Berlin, v. 51, n. 1, p. 67-81, 1997 b.

- A descoberta dos raios X: o primeiro comunicado de Röntgen. Revista Brasileira de Ensino de Física, São Paulo, v. 20, n. 4, p. 373-391, 1998a.

- Jevons e o papel da analogia na arte da descoberta experimental: o caso da descoberta dos raios X e sua investigação pré-teórica. Episteme, Porto Alegre, v. 3, n. 6, p. 222-249, 1998 b.

. Los errores experimentales de Henri Becquerel. In: GARCÍA, P.; MENNA, S. H.;

RODRÍGUEZ, V. (Ed.). Epistemología e historia de la ciencia. Selección de trabajos de las X Jornadas. Facultad de Filosofia y Humanidades. Córdoba: Universidad Nacional de Córdoba, 2000. v. 6. p. $267-$ 274.

. As primeiras investigações de Marie Curie sobre elementos radioativos. Revista da Sociedade Brasileira de História da Ciência, São Paulo, v. 1, n. 1, p. 29-41, 2003.

MARTINS, R. de A. \& SILVA, C. C. Newton and colour: the complex interplay of theory and experiment. Science \& Education, Dordrecht, v. 10, n. 3, p. 287-305, 2001.

MOREAU, G. De la photographie des objets métalliques à travers des corps opaques, au moyen d'une aigrette d'une bobine d'induction, sans tube de Crookes. Comptes Rendus Hebdomadaires des Séances de l'Académie des Sciences, Paris, v. 122, p. 238-239, 1896.

NIEWENGLOWSKI, G. H. Sur la proprieté qu'ont les radiations émises par les corps phosphorescents, de traverser certains corps opaques à la lumière solaire, et sur les expériences de M. G. Le Bon, sur la lumière noire. Comptes Rendus Hebdomadaires des Séances de l'Académie des Sciences, Paris, v. 122, p. 385-6, 1896.

PERRIN, J. Origine des rayons de Röntgen. Comptes Rendus Hebdomadaires des Séances de l'Académie des Sciences, Paris, v. 122, p. 716-7, 1896.

POINCARÉ, H. Les rayons cathodiques et les rayons Roentgen. Revue Générale des Sciences, v. 7, p. 52-9, 1896.

Les rayons cathodiques et les rayons Roentgen. Revue Scientifique, Paris, v. 4, n. 7, p. 72-81, 1897.

PUMFREY, S. History of science in the National Science Curriculum: a critical review of resources and aims. British Journal for the History of Science, London, v. 24, p. 61-78, 1991.

RAVEAU, C. Les faits nouvellement acquis sur les rayons de Roentgen. Revue Générale des Sciences, v. 7, p. 249-253, 1896. 
ROMER, A. (Ed.). The discovery of radioactivity and transmutation. New York: Dover, 1964. . Becquerel, [Antoine-] Henri. In: GILLIESPIE, C. C. (Ed.). Dictionary of Scientific Biography. New York: Charles Scribner's Sons, 1981, v. 2, p. 558-561. 16 v.

RÖNTGEN, W. C. Über eine neue Art von Strahlen. Sitzunsberichte der physikalisch-medicinischen Gesellschaft nach Würzburg, p. 132-141, 1895.

SAGNAC, G. Les expériences de M. H. Becquerel sur les radiations invisibles émises par les corps phosphorescents et par les sels d'uranium. Journal de Physique Théorique et Appliquée, Paris, v. 3, n. 5, p. 193-202, 1896.

SILVA, C. C. \& MARTINS, R. de A. A teoria das cores de Newton: um exemplo do uso da história da ciência em sala de aula. Ciência \& Educação, Bauru, v. 9, n. 1, p. 53-65, 2003.

STEWART, O. M. A résumé of the experiments dealing with the properties of Becquerel rays. Physical Review, New York, v. 6, p. 239-251, 1898.

THOMPSON, J. S. \& THOMPSON, H. G. Silvanus Phillips Thompson, his life and letters. London: T. Fisher Unwin, 1920.

THOMPSON, S. P. The Röntgen rays. Nature, London, v. 53, p. 437, 1896 a.

On hyperphosphorescence. Report of the 66th Meeting of the British Association for the Advancement of Science [66]: 713, $1896 \mathrm{~b}$.

. On hyperphosphorescence. The London, Edinburgh and Dublin Philosophical Magazine and Journal of Science, London, v. 5, n. 42, p. 103-107, 1896c.

THOMSON, J. J. Longitudinal electric waves, and Röntgen's X rays. Proceedings of the Cambridge Philosophical Society, London, v. 9, p. 49-61, 1896.

TOWNE, D. H. Teaching Newton's colour theory firsthand. American Journal of Physics, New York, v. 61, p. 113-116, 1993.

TROOST, L. J. Sur l'emploi de la blende hexagonale artificielle pour remplacer les ampoules de Crookes. Comptes Rendus Hebdomadaires des Séances de l'Académie des Sciences, Paris, v. 122, p. 564-566, 1896.

VIOLLE, J. L'oeuvre scientifique de M. Edmond Becquerel. Revue Scientifique, Paris, v. 49, p. 353-360, 1892.

WILSON, D. B. (Ed.). The correspondence between Sir George Gabriel Stokes and Sir William Thomson, Baron Kelvin of Largs. Cambridge: Cambridge University Press, 1990. 2 v. 